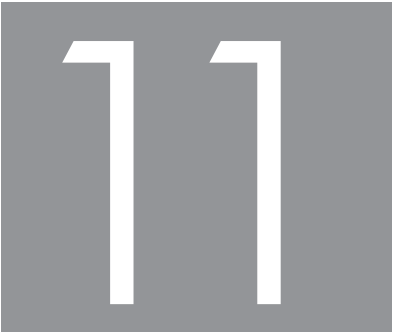

\title{
THE JOURNEYMAN AS A METAPHOR FOR DEVELOPING SKILLS IN POSTGRADUATE EDUCATION
}

\section{EXPERIENCE, FEEDBACK AND ROLE MODELS}

\section{Khalid El Gaidi}

\section{INTRODUCTION}

The number of $\mathrm{PhD}$ students has increased considerably during the last two decades in most countries in the world. In Sweden, it has nearly doubled during the same period while the number of supervisors remains almost unchanged. This change in ratio means that the $\mathrm{PhD}$ students have less time to spend with their supervisors in labs, less time for feedback and less time for jointly writing papers and developing a sense of quality in research than they had two decades earlier (UKÄ 2013:2). The decrease in available time for each $\mathrm{PhD}$ student to spend with his or her supervisor means that an important part of the informal, though important, close relationship between the two is now reduced to a strict minimum. Demands for efficiency drive the formalisation of the supervision process, which risks undermining the ground for efficient skills development.

To push the boundaries of PhD education, we need to devote special care to the resulting situation. The new conditions call for deepened insight into different components of knowledge, what role experience plays in the students' development and what kind of communication is needed to enable us as supervisors to use interaction time with PhD students more efficiently. Failing to do so and given the time restrictions, there is a risk that the skills transferred to coming generations of researchers will be watered down.

The purpose of this chapter is therefore to analyse PhD students' endeavour and suggest ways that may enable more efficient skill development, interaction and communication between a supervisor and a supervisee in research education.

The journeyman metaphor in this chapter belongs to a medieval system of production in Europe and may need some further explanation. Young apprentices entered 
trades at the age of ten to fourteen and would work for about seven years before they developed the skills necessary to qualify as a journeyman. If the piece of work (chef d'oeuvre) presented to the guild was accepted, they were given the journeyman's letter. The craftsman was now supposed to travel around in neighbouring countries for a further seven to ten years to work under the supervision of other masters in order to improve his skills even more. After this journey, he (gender intentional) would settle down and work on a masterpiece. If approved by the guild, he was allowed to open his own workshop and have apprentices (Sennett 2008:58).

The use of journeyman as a metaphor is motivated by the fact that skills in the workshop were the focus of the training and its aim was production. Learning is only a bi-product of the activity. As we will see later, training, communication and feedback were adapted to skills development. A few very isolated skill-dependent trades, such as conservatories of music, currently still practise the apprenticeship/journeyman model of education.

In the following, I will discuss the difference between skills and science, give a structured taxonomy of knowledge, proceed with a discussion on how a sense of quality is acquired, deal with critical aspects of skill and science, reflect on methodology and end with some concluding remarks.

\section{FROM SKILLS TO SCIENCE}

As a craft, skills are another form of knowledge. They are not science but an imperative prerequisite to producing it. Unlike scientific knowledge which is completely explicit, most of the skills are tacit. They are acquired by working together with more proficient practitioners, obtaining accurate and timely feedback as well as closely studying role models' artefacts.

Better than anyone, Nobel Prize Laureate Peter Medawar, in a reflective text, has captured the essence of skills:

... any scientist of any age who wants to make important discoveries must study important problems. But what makes a problem "important"? And how do you know when you see it? The answers don't come from reading in a book, nor even by explicitly being taught them. More often, they are conveyed by examples, through the slow accretion of mumbled asides and grumbled curses, by smiles, frowns, and exclamations over years of a close working relationship between an established scientist and his or her protégé (Kanigel 1993:xiv).

Most of the focus in postgraduate education is directed towards the tangible end-product of education: papers and theses. Every year, a number of books are 
published on how to write scientific papers and dissertations, adding to the huge number already on the bookshelves. The question is how helpful these books are for developing writing skills in postgraduate education.

When working with artificial intelligence and expert systems at the Massachusetts Institute of Technology (MIT) in the sixties, Hubert and Stuart Dreyfus developed a five-stage model, known as "from novice to expert", on how people acquire knowledge and skills in different knowledge areas. The novice is someone who is starting in a trade. After a while, he or she proceeds to advanced beginner and then to the competent stage. The two remaining stages are the skilled and the expert (Dreyfus \& Dreyfus 1986:16-51).The most interesting aspect of this model is that the knowledge development in the three first stages is accomplished by learning the rules (how the most common problems are solved) of the domain and trying to put them into practice. The skilled and experts already master the rules in practice and what they are interested in is the challenge of unsolved problems. This is mainly achieved intuitively.

Books for developing skills like scientific writing are filled with mechanical rules of writing. These may be helpful for learners in the early stages of the model. To move beyond this, writers should be encouraged to be creative and see the general in the specific and vice versa (Sennett 2008:247). The question is how this creativity is achieved.

Most of the 'how to' books on writing, however, ignore the fact that skills belong mainly to the tacit domain. Skilled people can demonstrate their skill but it is most of the times hard for them, if not impossible, to explain it. Skills are thus acquired by working responsibly with concrete tasks in concrete situations and obtaining adequate feedback from more proficient practitioners and by trying to emulate masterpieces produced by role models. In the same way, apprentices develop their craft skills under the supervision of a master to become journeymen. This is why a close relationship between a $\mathrm{PhD}$ student and a community of practice is of major importance. The language used to develop the craft is also specific. It is by concrete stories of how named journeymen and masters succeeded or failed to solve a specific task, not through abstract information that a sense of the quality of the trade is conveyed (Benjamin 1990:653).

Writing is but one example of all the skills necessary to develop to become an independent researcher. Before reaching the top skill of writing up, students have to acquire a range of other skills at different stages of the research process. Some of the questions that arise in this connection are: 


\section{PART FOUR • SUPERVISION STRATEGIES}

- How do we formulate relevant research questions?

- How do we arrive at the hypothesis to test?

- How do we design experiments?

- How do we discern patterns?

- How do we interpret experimental results?

- How do we develop scientific creativity?

- How do we assess quality in research?

- How do we develop ethical judgment?

- How do we develop independence in research?

Most of these skills and attitudes are reflected in the objectives of $\mathrm{PhD}$ education around the world. Skills and attitudes, as mentioned above, are not science in themselves but a necessary prerequisite to producing new scientific knowledge. Being another kind of knowledge, they require another kind of pedagogical communication to help PhD students to acquire them. Giving the student a book on scientific writing and expecting him or her to produce well-written scientific papers will result most of the time in frustration rather than well-written papers. The same applies to all the other skills and attitudes.

\section{A THREEFOLD VIEW ON KNOWLEDGE}

What, then, is the problem? The problem is that unlike scientific knowledge, skills cannot easily be fully described in words. Compare the answers to the following questions:

- How high is Mount Everest?

- Can you play tennis?

- How does the oboe sound?

These questions belong to different kinds of knowledge in the following taxonomy:

- Propositional knowledge

- Skills

- Familiarity

Giving 8848 metres above sea level as an answer to the first question lets us know all there is to know about this question.

This does not apply to the second question. What does a "Yes" as an answer stand for here? That you can hit the tennis ball with the racket? Or that you can challenge a professional tennis player, say Rafael Nadal, in a competition? The "Yes" can mean everything and nothing. Your proficiency in tennis should be "shown" rather 
than "told" to convey a meaning. In the absence of an opportunity to show your proficiency, concrete examples of your achievements will do. An adequate answer to the third question calls for the ability to imitate the sound of the oboe. This is almost impossible for most people without an instrument. Even with an instrument, it takes some training to produce a clear high $C$ on the oboe. But many amateurs of classical music will recognise the sound of the oboe if they hear it. They know it but cannot express it because it is tacit. In an investigation to find out if the Vienna Philharmonic Orchestra had a special "timbre", the researcher carried out many blind tests with different categories of people: laymen, amateur musicians and professional musicians. His conclusion was that the Vienna Philharmonic Orchestra indeed had a specific "timbre" that only a professional musician could identify when listening to the same instrument played by a member of the Vienna Philharmonic Orchestra (Bertsch 2002).

In the first category of this taxonomy (Johannessen 1999:88-90), propositional knowledge refers to the scientific knowledge that is explicit and that can be completely described in written form. The case is slightly different for the second question. Playing tennis is a skill and you have to show what you are able to perform to exhibit your skill and to give your "Yes" an experiential meaning. Familiarity associated with the third question is the ability to distinguish qualities among a series of similar artefacts. To be able to tell which sound belongs to the oboe takes some listening training. If the task, then, is to judge whether the oboe has the Vienna Philharmonic Orchestra timbre, the prerequisite is probably that you have played the same instrument at a professional level for years to be able to distinguish it (Bertsch 2002).

If we confine ourselves to the second question, what is important here is not only having the skill to play tennis but most importantly how we acquire that skill. The same applies to acquiring the skill of speaking a foreign language or writing scientific papers.

Reading a book about how to write scientific papers will probably help novice students structure their first step into the skill of writing up to a certain level and no more. These kinds of rules are to be found in all imaginable skills, whether they refer to grammar for language, the way chess pieces may move on a chessboard, or traffic signs.

However, the verbal mastery of these general rule sets does not make the owner proficient in the knowledge areas. It takes more than grammar to be a good writer, more than knowing how chess pieces are allowed to move on the chessboard to be a chess master, and more than knowing what traffic signs mean to be a good driver. The written rules of a knowledge area are called regulative rules (Janik 2002:273-284). 
Learning regulative rules may bring us up to the competency level but no more. A car driver with a fresh driving licence is a competent driver allowed to drive cars in the streets. Few, however, would consider our new driver to be proficient in driving cars. Car accident statistics show that young drivers are overrepresented in car crashes during the first few years of driving, a fact that insurance companies very well know. They charge them a higher premium for car insurance.

Regarding the two remaining stages of the novice-master model, the skilled and masters are known for being able to identify and solve problems intuitively. They know the rules of the trade, but what interests them is not already known and solved problems, but how to identify and solve new problems. They not only follow the rules, they create new ones along the way. The problem is that the kinds of rules they create are implicit in their artefacts, whether it be driving a car, writing a scientific paper, or playing tennis. The created rules, being implicit, make it hard if not impossible for novices and advanced beginners to distinguish and to learn from them. The kinds of rules they create are called constitutive rules. Their number is infinite and, therefore, it is hard to systematise and write them down. Most of the time they are implicit in the artefact, woven into narratives and studied as elements of style connected to role models; for example, books of or about world famous tennis players or violin virtuosos. Musicians, for instance, study for different masters and this record is often given in their curriculum vitae to show what tradition they represent.

Harriet Zuckerman, who studied Nobel Prize laureates, found that they had nothing in common with each other except that most of them seemed to come from labs led by former Nobel Prize winners (Zuckerman 1977:138-143). This conclusion is in line with Peter Medawar's cited above.

Now, if reading books about writing scientific papers does not help much in developing writing skills above a certain level, what should be done? There are three main areas for skills acquisition: working together with more proficient peers on authentic tasks in specific situations, receiving initiated and timely feedback from more proficient practitioners on writing and closely studying prototypical papers of role models and emulating their styles (Sennett 2008: 100).

One of the most efficient ways of learning skills is to work together with more proficient practitioners. Writing the first papers in collaboration with supervisors and post-docs provides the experience of sharing praxis. When co-authoring, PhD students gain a feeling for what is required by seeing all the thousands of small tacit decisions taken by researchers in the process of writing: why this word and not the other, why this argument and not the other and why this structure and not the other. In this process, constitutive rules of writing are imparted. The questions of the novice PhD students 
help the supervisor to put into words part of their skills and become aware of the knowledge they possess but seldom reflect on. Authentic tasks for developing skills, like presentation skills, are necessary since they give a sense of responsibility and sharpen the mind of the $\mathrm{PhD}$ students.

Working and receiving initiated feedback on what has been achieved is probably the single most important aspect of developing skills. To then develop their own styles, students benefit from closely studying masterpieces and discussing their elements in seminars.

\section{DEVELOPING A SENSE OF SCIENTIFIC QUALITY}

Even at preschool, children are proficient in their native language and can discriminate between those who speak the local dialect and those who do not. They master sets of rules such as pronunciation, grammar and syntax. No one has ever taught them these rules but the children have inferred them by experiencing an infinite number of occasions for learning the language in real-life situations and receiving feedback in the form of either words or body language when people do not understand what they mean. Unlike foreign languages learnt in school, the native language is used with confidence and without hesitation. On the other hand, learning a language, say Urdu, by relying solely on the words written in a book, without any feedback from the community of practice, will rarely lead to any intelligible use of the language at all.

The difference between learning a language, a skill, in the two situations described above is that the native language is learnt in a natural environment rich in authentic use in concrete situations, feedback and role models where all the tacit knowledge is transmitted down to subtle regional and dialectal nuances. The foreign language, on the other hand, is learnt from a book, which will not be able to contain or notate all the subtleties of language use. The mastery of the native language makes everybody an expert in a knowledge area: the use of their native language. As such, even preschool children are able to differentiate between the dialect spoken at home and other dialects from regions in the vicinity. This is the essence of familiarity, the attribute necessary for judging quality.

Inferring from learning the native language, we can conclude that the human brain is constructed to unconsciously create general rules and construct concepts when working with concrete situations, but not the other way round. Learning from concrete situations will enable learners to use their knowledge and skills without hesitation in new situations. Learning from abstract general rules, on the other hand, will not necessarily lead to recognising and handling problems in real life. 
Helping PhD students develop a sense of quality will mean exposing them to a variety of situations in science and the production of knowledge that give them authentic experience of quality. Concrete authentic situations where aspects of quality variation in research are experienced would include closely studying both good and bad papers in seminars, attending defences of theses and reflecting upon them in the research group, shadow-reviewing papers, with due authorisation, in parallel with senior researchers and comparing results. Like learning one's native language, the knowledge is given a shared experiential meaning.

\section{Role models, emulation and critical thinking}

What I have been describing so far is how important a close relationship is in a research community of practice, including supervisors, for skills development in $\mathrm{PhD}$ studies. I can hear virtual voices asking: Doesn't this close relationship in research groups undermine critical thinking - the hallmark of science? My short answer is "No", if it is done properly.

The use of "journeyman" as a metaphor for skills development in PhD studies has multiple layers. On the one hand, it stresses the "close relationship" between a master and an apprentice, authentic responsible work, stories associated with successes and failures of named individuals in the guild when dealing with special tasks, and rich and timely feedback. On the other hand, it also imparts an appreciation of the quality required.

Few skill-based domains of learning with a master-apprentice relationship remain today in our formalised information society. One that is still in existence, however, is conservatories of music.

To understand how skills are developed, the researcher conducted a study at the Royal Conservatory of Music (KMH) in Stockholm, Sweden. In one master class, students were required to play a piece of Baroque music (El Gaidi 2007:169-172). The teacher was not satisfied with the way the students played; she wanted them to play in the French style, not the Italian. The students looked puzzled. She went on to explain that the Italian way speeds up the tempo while the French expands the sound in the room. The explanation did not dissipate the puzzling fog from the four students' faces. She was compelled to use an analogy: "If the Italian way of playing is prose, the French way is poetry." The students looked even more puzzled. When she exhausted her words, she grabbed the violin and showed what she meant by playing the passage as she wanted them to play. The fog dissipated and their first attempt showed that they were on the right path, to the great satisfaction of the teacher. 
The second class was a quartet playing a piece of classical music. But the quartet was doubled by the teacher of each instrument. The tandems played in exactly the same way. The students had to adjust not only to the other instruments in the quartet but primarily to the teacher's way of playing. The third class was an octet. The group had a one-week practice assignment prior to class. The first thing the teacher said when starting the lesson was, "Could you please play through the piece so we have an opening bid?" The teacher listened attentively and when they had finished, he said, "Good, let us make some music out of this. By the way, somebody played an F-sharp in this passage, and there shouldn't be one." Magnus the cellist admitted immediately, "It was me". The teacher could hear a single false note. His legitimacy was unquestioned.

These three examples show what it means to work closely together, share practices, give feedback and talk about the artefact. This way of learning transfers not only the factual knowledge but also the style and the way of approaching the music that the master conveys to his or her disciples in the sessions.

But where is the critical thinking in all this?

The title "journeyman" gives us a hint about where to look for it. What journey? And why? When, after several years, the apprentice had his workpiece approved by masters in the guild, it was time for him to go off on a journey to other countries (in Europe) and work in the same trade under other masters for at least a year with each.

Working with the second master in a new country and mastering his style of solving problems in the trade not only gave the journeyman a new way of seeing his trade but liberated him from the style of his first master, of which until then he had hardly been aware. Additional mastery of subsequent masters' styles added new layers to the journeyman's frame of reference and independence. The system of a "journey" is thus the backbone of solid critical thinking in a journeyman's development. Back in his original country, it was time to settle down and prepare his masterpiece composed of elements of different masters' skills to form his own style. This process is a way of developing creativity.

It now becomes apparent that what we, in present-day academia, call 'post-doc' is nothing but a journeyman's system. This system could be used more consciously and systematically to foster independence in $\mathrm{PhD}$ students even before they have defended their thesis.

In modern-day science, there are many stories about how these elements have been transferred, not by scientific information, but by post-docs working in the labs of prominent scientists. One of these stories deals with Richard Feynman's diagrams. 
Richard Feynman, a prominent young physicist, was involved in Los Alamos in the 1940s. He has contributed substantially to atomic physics, solid state physics and gravitational physics. After the Second World War, he started to use small diagrams to keep track of the various mathematical equations he used to solve the tedious work of calculating the movements of atoms. Diagrams were a visual representation of the movements of particles over a period of time. Feynman presented his diagrams at the National Academy of Science in 1948.

But despite the presentation and despite the fact that the diagrams solved complicated calculations that physicists were struggling with around the world, they were not used. Their use during the first six years that followed was connected to Feynman's personal friendship with Freeman Dyson, an advocate of the Feynman diagrams who was working at the Institute of Advanced Studies in Princeton, New Jersey. Four of the five researchers that used these diagrams were post-docs with Freeman Dyson and had a personal relationship to him. In the Soviet Union, it took at least one year for the physicists to study the diagrams and many years to use them, and in Japan, it took much longer.

The spreading of the Feynman diagram is proof that even in theoretical sciences like physics there is a large portion of tacit knowledge that only spreads by working together and understanding the advantages and the limits of the use of such diagrams (Kaiser 2005).

\section{METHODOLOGY}

Basic data for the study reported in this chapter was collected in a series of seminars. The researcher met with three experienced supervisors in five dialogue seminars of five hours each to reflect on what skills and attitudes are required for research and how to scaffold their development in $\mathrm{PhD}$ education. The participants had to complete reading and writing assignments for each of the five meetings. At the meeting, the participants read their text in the seminar and a dialogue followed. Minutes of the dialogues were written for each meeting. These minutes and the texts were later analysed and interpreted by the researcher using a hermeneutical method (Little 2008). Additional data was collected from a supervisors' course taught by the researcher at the Royal Institute of Technology in Stockholm, Sweden (KTH). More than five hundred supervisors have taken the course and each has produced at least three texts.

Another important aspect of the methodology concerns what the researcher is looking for in the data and how the findings are communicated. Let me give an example: one supervisor reported that a paper had been iterated 34 times between 
himself and his PhD student. "Being clear" in his feedback, the supervisor expected the $\mathrm{PhD}$ student to amend the paper in accordance with his instructions to make it acceptable for submission. And each time he reviewed the paper, he could see that the student had not understood.

Thirty-four iterations is probably an extreme case, but a number of iterations are quite common. What, then, is the problem? The problem, as pointed out by Wittgenstein, is that we only understand language propositions through our experience. Rules do not come with (rules) describing how they should be used (Wittgenstein 2009: para. 202). This means that if we do not share experiences we have no way of understanding each other properly. That is why the proposed way of writing papers together, sharing experiences at the beginning of PhD studies, giving timely and accurate initiated feedback and closely studying prototypical papers written by role models is important.

This idea is also valid for communication, whether it is scientific or informal. The use of authentic experience and concrete examples when communicating with $\mathrm{PhD}$ students makes the communication stringent and reduces the area of (mis-) interpretation, thus making communication more effective.

The other aspect of communication is that what a person understands as criteria for quality is what he or she is able to produce. No other understanding is possible. Remember the master classes in music and how the teacher, who was not able to "explain" what she meant by the French way of playing, was instead compelled to "show" the students before they understood. PhD students' understanding of writing quality is evidenced by what they are able to produce, nothing else. If supervisors wait until they see what their students produce as a result of their feedback, they will be spared much frustration.

These two aspects of communication are universal and apply to all communication in all situations. They concern the relationship between language propositions and experience, the theme of Wittgenstein's later work, "Meaning is use" (Wittgenstein 1977:317).

The use of experience and concrete examples in the social sciences should not be looked upon as less worthy since it is anecdotal. It is necessary to give abstract generalisations a strict meaning. This is the difference between the two kinds of language used in the former skill-based workshop and the industrial method of production widely dominating today. The former used "concrete stories" and the latter "abstract information", as pointed out by Walter Benjamin (Benjamin 1990:653). This seems to be the root of much trouble in learning and communication in general today. 
A final and important aspect of the methodology is the use of analogical thinking. Finding good analogies and praxis helps shed light on the practice one is studying. Using, for example, the teaching practices from the Royal Conservatory of Music in Stockholm was a source of more than one insight.

\section{CONCLUDING REMARKS}

It is not by chance that the objectives of PhD education in Sweden (and most countries in the world) are divided into three categories: scientific knowledge, skills and attitudes. These categories belong to different kinds of knowledge. Each has its specificities and requires special attention in communication and development.

Among the skills and attitudes enumerated in the educational objectives, one can find communication, critical thinking, creativity and ethical judgment. By experience, we know that many more than the skills like those enumerated above are needed to conduct successful scientific research. Most of the time these skills are taken for granted and not mentioned at all. In this chapter, I have only written about skills. Attitudes such as those in ethics are not addressed - they will be the theme of a paper to come.

To properly help PhD students develop the skills they require, and with the presentday time restrictions, we as supervisors have to recognise the different nature of skills, develop knowledge about how to acquire them, design adequate experiences and provide the students with opportunities to reflect about their learning. Failing to do so may lead to much frustration and perturbed communication - and ultimately failure.

\section{REFERENCES}

Benjamin W. 1990. Paris, 1800-talets huvudstad: Passagearbetet (Das Passagen-Werk). (Paris, capital of the nineteenth century - The Arcades project).

Bertsch M. 2002. Can you identify the Vienna Philharmonic Orchestra compared to the Berlin or New York Philharmonic? [Accessed 13 May 2013] http://iwk.mdw.ac.at/lit_db_iwk/

Dreyfus HL \& Dreyfus ES. 1986. Mind over machine. New York: The Free Press.

El Gaidi K. 2007. Lärarensyrkeskunnande - Bildningochreflekteradeerfarenheter. Stockholm: Dialoger.

Janik A. 2002. Dialoger. In: P Tillberg (ed). Tyst kunskap, regelföljande och inlärning. Stockholm: Industriell ekonomi och organisation Yrkeskunnande och Teknologi. 273-284.

Johannessen KS. 1999. Praxis och tyst kunnande (Praxis and tacit knowledge). Stockholm: Dialoger.

Kaiser D. 2005. Doing physics with Feynman's diagrams. American Scientist, 93:156-164.

Kanigel R. 1993. Apprentice to genius. Baltimore, MD: John Hopkins University Press. 
Sennett R. 2008. The craftsman. New Haven, CT: Yale University Press.

UKÄ (UniversitetsochHögskoleämbetet). 2013. UKÄ-rapport. [Accessed 13 May 2013] http:// www.uk-ambetet.se /statistikuppfoljning/arsrapportforuniversitetochhogskolor.4.782a2988 13a88dd0dad800011775.html

Little D. What is hermeneutic explanation? [Accessed 21 January 2014] http://www-personal. umd.umich.edu/ delittle/Encyclopedia\%20entries/hermeneutic\%20explanation.htm

Wittgenstein L. 1977. Bemerkungenüber die Farben (Remarks on colour). Oxford: Basil Blackwell.

Wittgenstein L. 2009. Philosophical investigations. Malden, MA: Blackwell.

Zuckerman H. 1977. Scientific elite: Nobel laureates in the United States. New York: The Free Press. 